
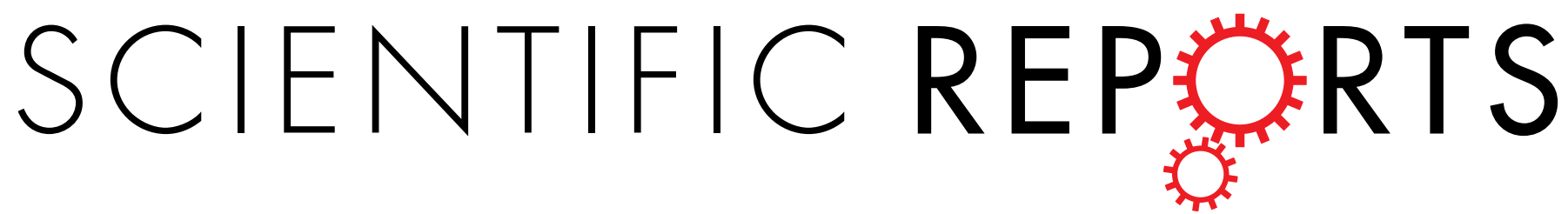

\title{
OPEN Dietary patterns and the risk of rhinitis in primary school children: a prospective cohort study
}

Received: 21 October 2016

Accepted: 10 February 2017

Published: 15 March 2017

\section{Xudong Liu ${ }^{1}$, Claudie Chiu-Yi Wong ${ }^{1}$, Ignatius T. S. Yu ${ }^{1,2}$, Zilong Zhang ${ }^{1}$, Lixing Tan ${ }^{1}$, Arthur P. S. Lau ${ }^{3}$, Albert Lee ${ }^{1}$, Eng Kiong Yeoh ${ }^{1}$ \& Xiang Qian Lao ${ }^{1}$}

This study was to investigate the association between dietary patterns and rhinitis in primary school children. 1,599 students without rhinitis at baseline survey were selected from a primary school children cohort. Information on food consumption, respiratory symptoms, and confounders was collected using questionnaires. Dietary patterns were defined using principal component analysis. Logistic regression was performed to calculate odds ratio (OR) with $95 \%$ confidence intervals $(95 \% \mathrm{CI})$. The incidence of rhinitis during 12 months follow-up was $21.2 \%$. Three patterns were extracted and labeled as pattern I, II and III. Dietary pattern II which had higher factor loadings of legumes, butter, nuts and potatoes was associated with an increased risk of rhinitis (OR: 1.34, 95\% Cl: 1.01-1.87) when the highest tertile of pattern score was compared to the lowest tertile, after adjusted for confounders. Besides, every 1-unit increase of score of pattern II was also associated with an increased risk of rhinitis (OR: 1.19, 95\% Cl: 1.05-1.35). Neither pattern I nor Pattern III was observed to be associated with risk of rhinitis. A diet with higher levels of consumption of legumes, butter, nuts and potatoes may increase the risk of allergic rhinitis in primary school children.

Asthma and atopic respiratory disorder have become more prevalent worldwide, affecting nearly 235 million people $^{1,2}$. It is estimated that $14 \%$ of the world's children were likely to have had asthmatic symptoms ${ }^{2}$. The high prevalence of asthma has been associated with an increase in atopic sensitization, and is paralleled by similar increases in other allergic disorders such as rhinitis and eczema. Asthma has created a heavy global burden and affected the quality of human life significantly, especially in children ${ }^{3,4}$. Allergic rhinitis is defined as inflammation of the nasal mucous membrane that appears after the exposure to a particular allergen other than an infection. Although it has received less attention than asthma in epidemiological studies, allergic rhinitis is recognized as the most common allergic manifestation in children and it is highly correlated with asthma ${ }^{5,6}$.

Various factors have been reported to be related to asthma and allergy disease in children. In particular, increasing evidence has highlighted a crucial role for both maternal and childhood food exposure as protection against the development of allergic diseases ${ }^{7}$. A considerable number of epidemiological studies have reported the protective effects by intake of individual nutrients ${ }^{8,9}$ and individual food item ${ }^{9-12}$ during later childhood. Dietary pattern which represents a whole profile of a diet might be more useful to study the association between diet and health outcome, because dietary pattern can in some degree reflect the interactions among different foods or different nutrients ${ }^{13,14}$. Current study found that both indexed-based patterns, such as the Mediterranean diet pattern $^{15-18}$, and patterns defined by using posterior approaches ${ }^{19-22}$ might have impacts on asthma and other allergic sensitization. However, studies on the association between Mediterranean diet and rhinitis in school-aged children did not obtain conclusive results: for example, in adherence to a Mediterranean dietary pattern was inversely associated with rhinitis and other atopic disease in Mexican children ${ }^{15}$ and Greece children ${ }^{23}$, whereas such association was not observed in Turkey children ${ }^{24,25}$. Conflicted results were also observed on the association of Mediterranean diet during pregnancy and children rhinitis ${ }^{26}$.

Empirical dietary patterns have mostly commonly defined by using principle component analysis, factor analysis and cluster analysis. Unlike the index-based patterns which paly a particularly important role in evaluating dietary guidelines and recommendations, dietary patterns defined by using posterior data-driven method can

${ }^{1} \mathrm{JC}$ School of Public Health and Primary Care, The Chinese University of Hong Kong, Hong Kong SAR, China. ${ }^{2}$ Hong Kong Occupational and Environmental Health Academy, Hong Kong SAR, China. ${ }^{3}$ Division of Environment, Hong Kong University of Science and Technology, Hong Kong SAR, China. Correspondence and requests for materials should be addressed toX.Q.L. (email:xqlao@cuhk.edu.hk) 


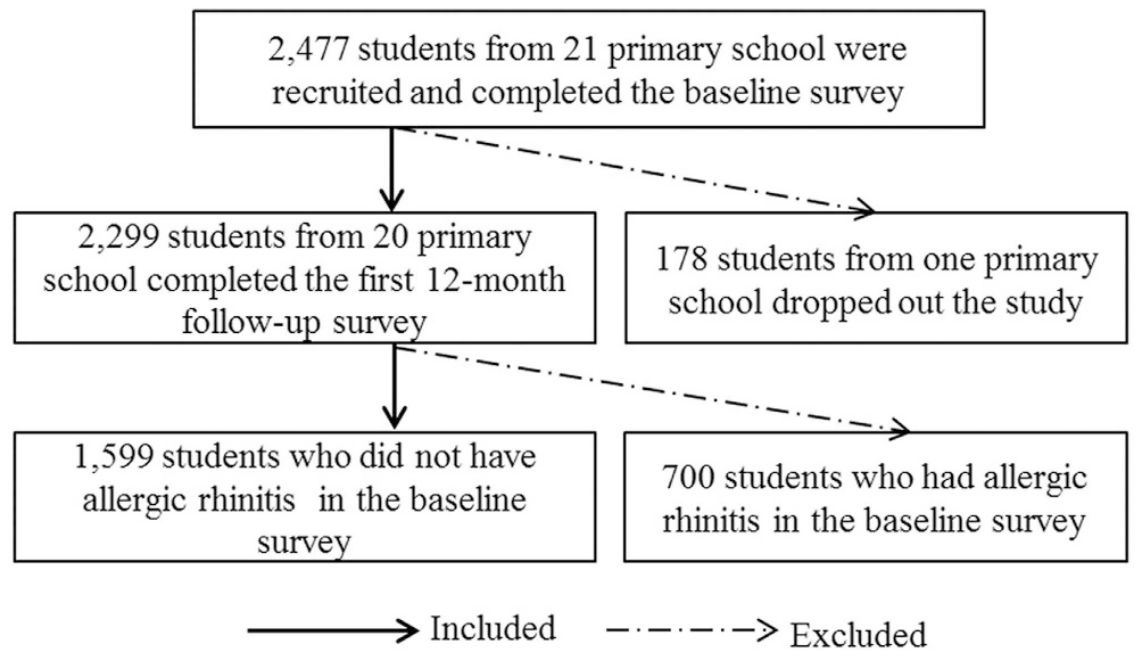

Figure 1. The flow chart of participants' selection. Solid arrow represents the process of including students; dashed arrow represents the process of excluding students.

reflect the real nutritional or dietary information within a population in a certain period ${ }^{27}$. However, in children, there was only limited evidence on the association between rhinitis and posterior dietary patterns ${ }^{21}$. We, therefore, conducted a prospective cohort study to investigate the association between dietary pattern defined by posterior approach and risk of rhinitis in school-aged children.

\section{Methods}

Study setting and participants. The study is based on an ongoing longitudinal prospective cohort in Hong Kong primary school children. The details of this study have been described elsewhere ${ }^{28-30}$. Briefly, twenty-one primary schools were randomly selected with a wide geographical coverage in Hong Kong. To facilitate the spirometry test and the follow-up, students from grades two to four were invited to participate in the study and a total of 2,477 students were recruited in the baseline (Fig. 1). Students were followed up annually for a period of two years after their recruitment. One school (178 students) withdrew during the follow-up. At the end of 2014, 2,299 students from the 20 schools had successfully completed both the baseline and the first-round follow-up surveys, with one year apart. The general characteristics (including age, sex, and education of parents) were similar between the drop out students and the students completed the follow-up survey. Among the 2,299 students, we excluded the $700(30.4 \%)$ students who had rhinitis in the previous 12 months prior to the baseline survey. Thus a total of $1,599(69.6 \%)$ students who did not have allergic rhinitis in the baseline survey and who completed both the baseline and the first follow-up survey were then included in the present analysis. The Joint Chinese University of Hong Kong-New Territories East Cluster Clinical Research Ethics Committee approved this study (Approval ID: 2013.193). This study met the requirements of the Declaration of Helsinki and a written informed consent for each student was signed by their parents.

Data collection. A structured questionnaire was used to collect a wide range of information during the previous 12 months, including social-demographics, respiratory symptoms, self-reported doctor-diagnosed respiratory diseases, and factors affecting air quality in the home environment. The items in the questionnaire were mainly adopted from the survey tools of the International Study of Asthma and Allergies in Childhood (ISAAC), American Thoracic Society, and the European Community Respiratory Health Survey ${ }^{31-33}$. A simple food frequency questionnaire used in an ISAAC phase three study ${ }^{34}$ was also adopted to collect information on the habits of dietary consumption during the past 12 months. The food items in the question were suitable for children in different regions, including children in Hong Kong ${ }^{35,36}$. Parents were required to answer the questionnaire together with their children at home. We also performed a pilot study on 77 children with two-week interval to test the reproducibility of food frequency questionnaire. A moderate association (spearman correlation coefficients $\geq 0.77$ ) and a moderate inter-rate agreement (kappa statistics $\geq 0.40$ ) were observed according to suggestion by DeVellis ${ }^{37}$ and Altman ${ }^{38}$. In addition to filling in the questionnaires, each student received a simple health examination to measure his/her weight and height at school in baseline and follow-up surveys.

Rhinitis ascertainment. Rhinitis, referring in particular to non-infectious rhinitis in the present study, was defined as affecting those children who have "ever had nasal symptoms such as nasal blockage, sneezing, and a runny nose as well as itching eyes or lachrymation in the absence of a common cold in the previous 12 months". Those who responded "Yes" were further asked one additional question to confirm their response: please indicate the months when your child suffered from rhinitis with 12 month options provided. We compared the responses to two questions. Only those children whose responses to two questions were consistent were deemed to have rhinitis during the 12-month follow-up. 
Dietary exposures. The question "Generally, how often have you consumed the following food groups in the past 12 months?" was used to collect information on dietary intake. A total of 13 groups of food were used in the simple food frequency questionnaire: meat (including pork, beef, lamb, chicken, duck and et al.), seafood (including fish, shrimp and et al.), fruit (including citrus and non-citrus fruits), vegetables (including leaf vegetables, tuber vegetables, gourd and solanaceae vegetables, green vegetables and et al.), legumes (including soy, beans, peas and their products), cereals (including cereals products), rice (including rice products), butter (including margarine), nuts (including peanuts, true nuts and et al.), potatoes, milk, eggs and fast food (such as McDonalds, KFC and Subway). The questionnaire assessed weekly consumption using a three-level scale: less than once per week $(<1 /$ week), once to twice per week ( $<3 /$ week) and thrice or more per week ( $\geq 3 /$ week).

Potential confounding factors. Potential confounders collected from the questionnaire included social-demographic characteristics (age, gender, education level of parents, and average size of house for each member), factors affecting air quality in the home environment in the past 12 months (whether there were plants, pets, incense or mosquito coils burning, new furniture or home renovation, carpet, and mold observation), passive smoking, family history of atopic disease (asthma, allergic rhinitis and eczema), other respiratory diseases (defined as self-reported doctor-diagnosed eczema, bronchitis, bronchiolitis, pneumonia, asthma and wheezing). Weight and height were used to calculate body mass index $\left(\mathrm{kg} / \mathrm{m}^{2}\right)$. Additionally, the concentration of particles matters less than 2.5 micrometers in diameter $\left(\mathrm{PM}_{2.5}, \mu \mathrm{g} / \mathrm{m}^{2}\right)$ on the school campus was measured in the baseline survey using a Dust Trak (TSI) aerosol monitor. To address seasonal variation, we conducted two measurements; one was in the cool season (winter or spring) and the other in the warm season (summer or autumn). The average concentration of $\mathrm{PM}_{2.5}$ in each school was used in the present analysis. The total chemical burden score was defined to indicate cumulative weekly exposure level to the 14 types of chemical cleaning products for each participant and was calculated by the method describe in our previous report ${ }^{39}$. The information of weekly usage frequency and average duration of each use were collected by using questionnaire; then total chemical burden score was calculated by using the following formula: total chemical burden score $=\sum_{i=1}^{14}\left(\right.$ Frequency $_{i} \times$ Duration $\left._{i}\right)$, where Frequency refers to the weekly frequency of usage of a certain chemical product, Duration refers to the average duration of each use, and $i$ represents the specific chemical cleaning product.

Statistical analysis. All statistical analyses were performed using R-software (version 3.1.3). $P$-values were derived from two-sided statistic tests and less than 0.05 was considered to be statistically significant.

In order to derive the dietary patterns of the students from the categorical responses of food intake frequency, a simple score for the intake frequency of each kind of food was defined $(1=$ less than once per week, $2=$ once to twice per week, $3=$ at least three times per week). The dietary patterns were then extracted using the principal components analysis (PCA) ["psych" package] based on 13 groups of food. Orthogonal (varimax) transformation was adopted to achieve a simple structure with greater interpretability. To determine the number of factors to retain, eigenvalues ( $>$ 1.0 ), the scree plot construction, Kaiser-Meyer-Olkin measure of sampling, Bartlett's test of sphericity, and the interpretability of the factors were considered ${ }^{40}$. The dietary pattern score of each student was calculated using the regression method. Food items with absolute rotated factor loadings $\geq 0.53$ are referred to as "dominant components" hereafter. The labeling of factors was based on our interpretation of the data. A positive loading for a food item indicated a direct association with the pattern, whereas a negative loading suggested that food contributed inversely to the pattern. The scores of dietary patterns were then reverted to categorical variables using the tertile method.

Logistic regression ["aod" package] was performed to assess the relationship between the dietary factors (including individual food items and dietary patterns) and rhinitis. Unadjusted relative risk (OR) and adjusted OR with $95 \%$ confidence intervals $(95 \% \mathrm{CI}$ ) were calculated in the univariate and multivariable models, respectively. In multivariable model, we firstly adjusted for only the potential confounders, and then adjusted for both confounders and three dietary patterns. In addition, the categories of food or dietary pattern score were included as numerical variable in the logistic model to test for linear trend. In order to ascertain whether there was any interaction between dietary patterns and gender or and age, we included the term "dietary pattern score $\times$ gender" and "dietary pattern score $\times$ age" in the models separately. However, no interaction was observed (all $P>0.05$ ). Students were categorized into subgroups based on gender (male, female) or median of age ( $\leq 9$ years, $>9$ years) and stratified analyses were performed. Sensitivity analysis was done by removing those who had other respiratory diseases and by removing those who had family history of atopic diseases.

\section{Results}

During the follow-up period of 12 months, the incidence of rhinitis was $21.2 \%$ (339). Besides, 270 students had other respiratory disease ( 90 had bronchitis, 28 had bronchiolitis, 36 had pneumonia, 125 had eczema and 51 had wheezing). The mean (S.D.) age of the 1599 students was 9.0 (1.0) years, ranging from 7.8 to 14.0 years. No significant difference in age was observed between genders $(p>0.05)$. The general characteristics of the students are presented in Table 1.

In comparison with the rice consumption of less than once per week, the rice consumption of thrice or more per week was associated with a reduced risk of rhinitis (OR: $0.23,95 \% \mathrm{CI}: 0.09-0.55, P_{\text {-trend: }}: 0.016$ ) after adjusting for all potential confounders as well as 13 groups of foods (Table 2). Other 12 foods were not observed to be associated with risk of rhinitis.

Supplementary Table S1 presents the rotated factor loadings using principle component analysis. Three factors were defined. The first factor was characterized with a higher factor loading of meat, seafood, fruit, vegetables, cereals, rice, milk and eggs, explaining about $40 \%$ of total variance, labeled as Pattern I. The second factor was characterized with a higher factor loading of legumes, butter, nuts and potatoes, explaining about $16 \%$ of the 


\begin{tabular}{|c|c|c|c|c|}
\hline \multirow[b]{2}{*}{ Items } & \multicolumn{3}{|c|}{ Value } & \multirow[b]{2}{*}{ P value } \\
\hline & Total & Non- $\mathbf{h}^{*}$ & $\mathbf{R h}^{*}$ & \\
\hline & \multicolumn{4}{|c|}{ Mean (standardized deviation) } \\
\hline Age, years & $9.0(1.0)$ & $9.0(0.9)$ & $9.0(1.0)$ & $0.557^{\dagger}$ \\
\hline Body mass index, $\mathrm{kg} / \mathrm{m}^{2}$ & $17.3(3.1)$ & $17.3(3.1)$ & $17.3(3.2)$ & $0.990^{\dagger}$ \\
\hline $\begin{array}{l}\text { Average size of house for each } \\
\text { member, } \mathrm{m} 2\end{array}$ & $9.4(4.1)$ & $9.4(4.1)$ & $9.6(3.8)$ & $0.363^{\dagger}$ \\
\hline \multirow[t]{2}{*}{$\begin{array}{l}\text { Concentration of PM2.5 in each } \\
\text { school }(\mu \mathrm{g} / \mathrm{m} 2)\end{array}$} & $54.9(42.0)$ & $55.0(40.6)$ & $54.6(46.9)$ & $0.557^{\dagger}$ \\
\hline & \multicolumn{4}{|c|}{ Median (Interquartile) } \\
\hline \multirow[t]{2}{*}{ Total chemical burden score } & $3.2(2.2)$ & $3.1(2.2)$ & $3.4(2.6)$ & $0.233^{*}$ \\
\hline & \multicolumn{4}{|c|}{ Number (Percentage \%) } \\
\hline Gender, male & $738(46.2)$ & $578(45.9)$ & $160(47.2)$ & $0.709^{5}$ \\
\hline Passive smoking at home, yes & $316(19.8)$ & $246(19.5)$ & $70(20.6)$ & $0.700^{\S}$ \\
\hline Keeps a pet at home, yes & $151(9.4)$ & $118(9.3)$ & $33(9.7)$ & $0.919^{\S}$ \\
\hline Has a plant at home, yes & $709(44.3)$ & $565(44.8)$ & $144(42.5)$ & $0.474^{\S}$ \\
\hline $\begin{array}{l}\text { Burns incense/mosquito coils at } \\
\text { home, yes }\end{array}$ & $362(22.6)$ & $293(23.3)$ & $39(20.4)$ & $0.289^{\S}$ \\
\hline $\begin{array}{l}\text { Has new furniture or renovation at } \\
\text { home, yes }\end{array}$ & $357(22.3)$ & $282(22.4)$ & $75(22.1)$ & $0.943^{\S}$ \\
\hline Has carpet at home, yes & $257(16.1)$ & $204(16.2)$ & $53(15.63)$ & $0.870^{\S}$ \\
\hline Has mould at home, yes & $574(35.9)$ & $445(35.2)$ & $129(38.1)$ & $0.375^{\S}$ \\
\hline Weekly physical activity & & & & $0.629^{\S}$ \\
\hline Never/less than once & $450(28.1)$ & $353(28.0)$ & $97(26.6)$ & \\
\hline Once or twice & $866(54.2)$ & $678(53.8)$ & $188(55.5)$ & \\
\hline At least three times & $283(17.7)$ & $229(18.2)$ & $54(15.9)$ & \\
\hline Education of father & & & & $0.540^{\S}$ \\
\hline Primary school or below & $146(9.1)$ & $113(9.0)$ & $33(9.7)$ & \\
\hline Secondary school & $1,206(75.4)$ & $958(76.0)$ & $248(73.2)$ & \\
\hline Tertiary school or above & $247(15.4)$ & $189(15.0)$ & $58(17.0)$ & \\
\hline Education of mother & & & & $0.518^{\S}$ \\
\hline Primary school or below & $194(12.2)$ & $148(11.7)$ & $46(13.6)$ & \\
\hline Secondary school & $1,190(74.4)$ & $938(74.4)$ & $252(74.3)$ & \\
\hline Tertiary school or above & $215(13.4)$ & $174(13.8)$ & $41(12.1)$ & \\
\hline Other respiratory disease, yes & $239(14.9)$ & $175(13.9)$ & $95(28.0)$ & $<0.001^{\S}$ \\
\hline Family history of atopic disease & $138(8.6)$ & $101(8.0)$ & $37(10.9)$ & $0.1145^{\S}$ \\
\hline
\end{tabular}

Table 1. Basic characteristics of the study subjects in baseline survey. ${ }^{*} \mathrm{Rh}$ : rhinitis. ${ }^{\dagger} P$-value from Welch's t-test between students with and without rhinitis. ${ }^{\ddagger} P$-value from Wilcoxon rank sum test with continuity correction between students with and without rhinitis. ${ }^{\circledR} P$-value from Pearson's Chi-squared test with Yates' continuity correction between students with rhinitis and students without rhinitis.

total variance, labeled as Pattern II. The third factor was characterized with a higher factor loading of fast food, explaining about the $9 \%$ of the total variance, labeled as Pattern III.

Table 3 presents the relationship between dietary patterns and the risk of rhinitis. After adjusting for potential confounders, every 1-unit increase of score of pattern II was significantly associated with an increased risk of rhinitis (OR: 1.19, 95\% CI: 1.05-1.35). By comparing the highest tertile with the lowest tertile of pattern scores, pattern II was also associated with an increased risk of rhinitis (OR: 1.34, 95\% CI: 1.01-1.87). Neither pattern I nor Pattern III was observed to be related to the risk of rhinitis. Besides, when considering confounders and all of three patterns, simultaneously, no significant change in effects was observed for all of three patterns.

In sensitivity analysis, similar results were obtained when the analysis was done by removing students who had other respiratory diseases (Supplementary Table S2) and by removing those who had family history of atopic diseases (Supplementary Table S3). In stratified analysis based on the median of the age (Supplementary Table S4) and on the gender (Supplementary Table S5), similar results were observed. Every 1-unit increase of score of pattern II was significantly associated with an increased risk of rhinitis, though the effect in females was marginally significant.

\section{Discussion}

In this prospective cohort study, we studied the association between dietary patterns defined by principle component analysis and risk of allergic rhinitis in school-aged children. Our results show that dietary pattern II which had a higher factor loading of legumes, butter, nuts, and potatoes was associated with an increased risk of rhinitis. No significant association was observed for other two dietary patterns. 


\begin{tabular}{|c|c|c|c|c|}
\hline Foods & $\mathrm{N}(\text { Yes/No })^{*}$ & Unadjusted $\mathrm{OR}_{1}(95 \% \mathrm{CI})^{\dagger}$ & Adjusted $\mathrm{OR}_{2}(95 \% \mathrm{CI})^{\ddagger}$ & Adjusted $\mathrm{OR}_{3}(95 \% \mathrm{CI})^{\mathrm{s}}$ \\
\hline \multicolumn{5}{|l|}{ Meat } \\
\hline$<1 /$ week & $65 / 248$ & 1.00 & 1.00 & 1.00 \\
\hline 1 2/week & $58 / 222$ & $1.00(0.67,1.48)$ & $1.30(0.79,2.16)$ & $0.21(0.03,1.63)$ \\
\hline$\geq 3 /$ week & $216 / 790$ & $1.04(0.77,1.43)$ & $1.31(0.84,2.07)$ & $1.75(0.84,3.84)$ \\
\hline$P$ for trend & & 0.755 & 0.321 & 0.214 \\
\hline \multicolumn{5}{|l|}{ Seafood } \\
\hline$<1 /$ week & $91 / 350$ & 1.00 & 1.00 & 1.00 \\
\hline 1 2/week & $137 / 509$ & $1.04(0.77,1.40)$ & $1.21(0.85,1.73)$ & $1.75(0.86,3.78)$ \\
\hline$\geq 3 /$ week & $111 / 401$ & $1.06(0.78,1.46)$ & $1.23(0.85,1.80)$ & $1.21(0.78,1.92)$ \\
\hline$P$ for trend & & 0.695 & 0.324 & 0.506 \\
\hline \multicolumn{5}{|l|}{ Fruits } \\
\hline$<1 /$ week & $69 / 236$ & 1.00 & 1.00 & 1.00 \\
\hline $1 \sim 2 /$ week & $56 / 231$ & $0.83(0.56,1.23)$ & $0.94(0.57,1.54)$ & $1.21(0.76,1.96)$ \\
\hline$\geq 3 /$ week & $214 / 793$ & $0.92(0.68,1.26)$ & $1.04(0.68,1.61)$ & $0.90(0.44,1.91)$ \\
\hline$P$ for trend & & 0.767 & 0.67 & 0.749 \\
\hline \multicolumn{5}{|l|}{ Vegetables } \\
\hline$<1 /$ week & $65 / 229$ & 1.00 & 1.00 & 1.00 \\
\hline $1 \sim 2 /$ week & $39 / 121$ & $1.14(0.72,1.78)$ & $1.32(0.75,2.32)$ & $0.97(0.48,2.03)$ \\
\hline$\geq 3 /$ week & $235 / 910$ & $0.91(0.67,1.25)$ & $1.03(0.66,1.61)$ & $1.36(0.62,3.14)$ \\
\hline$P$ for trend & & 0.417 & 0.717 & 0.507 \\
\hline \multicolumn{5}{|l|}{ Beans } \\
\hline$<1 /$ week & $116 / 451$ & 1.00 & 1.00 & 1.00 \\
\hline $1 \sim 2 /$ week & $164 / 616$ & $1.04(0.79,1.35)$ & $1.10(0.81,1.50)$ & $0.96(0.45,2.15)$ \\
\hline$\geq 3 /$ week & $59 / 193$ & $1.19(0.83,1.69)$ & $1.28(0.86,1.90)$ & $1.05(0.73,1.52)$ \\
\hline$P$ for trend & & 0.384 & 0.228 & 0.974 \\
\hline \multicolumn{5}{|l|}{ Cereals } \\
\hline$<1 /$ week & $64 / 229$ & 1.00 & 1.00 & 1.00 \\
\hline 1 2/week & $68 / 267$ & $0.91(0.62,1.34)$ & $1.09(0.66,1.82)$ & $1.02(0.64,1.64)$ \\
\hline$\geq 3 /$ week & $207 / 764$ & $0.97(0.71,1.34)$ & $1.12(0.70,1.79)$ & $1.30(0.59,3.05)$ \\
\hline$P$ for trend & & 0.954 & 0.674 & 0.989 \\
\hline \multicolumn{5}{|l|}{ Rice } \\
\hline$<1 /$ week & $76 / 224$ & 1.00 & 1.00 & 1.00 \\
\hline $1 \sim 2 /$ week & $12 / 66$ & $0.54(0.26,1.01)$ & $0.43(0.20,0.89)$ & $1.17(0.54,2.68)$ \\
\hline$\geq 3 /$ week & $251 / 970$ & $0.76(0.57,1.03)$ & $0.63(0.41,0.97)$ & $0.23(0.09,0.55)$ \\
\hline$P$ for trend & & 0.116 & 0.098 & 0.016 \\
\hline \multicolumn{5}{|l|}{ Butter } \\
\hline$<1 /$ week & $231 / 891$ & 1.00 & 1.00 & 1.00 \\
\hline 1 2/week & $92 / 316$ & $1.12(0.85,1.47)$ & $1.10(0.82,1.46)$ & $0.38(0.21,0.70)$ \\
\hline$\geq 3 /$ week & $16 / 53$ & $1.16(0.63,2.03)$ & $1.12(0.60,2.00)$ & $1.03(0.74,1.42)$ \\
\hline$P$ for trend & & 0.366 & 0.514 & 0.707 \\
\hline \multicolumn{5}{|l|}{ Nuts } \\
\hline$<1 /$ week & $248 / 975$ & & & \\
\hline $1 \sim 2 /$ week & $76 / 256$ & $1.17(0.87,1.56)$ & $1.23(0.90,1.67)$ & $0.91(0.46,1.72)$ \\
\hline$\geq 3 /$ week & $15 / 29$ & $2.03(1.05,3.79)$ & $2.48(1.24,4.76)$ & $1.16(0.82,1.63)$ \\
\hline$P$ for trend & & 0.038 & 0.011 & 0.108 \\
\hline \multicolumn{5}{|l|}{ Potatoes } \\
\hline$<1 /$ week & $161 / 629$ & 1.00 & 1.00 & 1.00 \\
\hline 1 2/week & $148 / 556$ & $1.04(0.81,1.34)$ & $1.07(0.81,1.41)$ & $1.74(0.81,3.64)$ \\
\hline$\geq 3 /$ week & $30 / 75$ & $1.56(0.98,2.45)$ & $1.90(1.16,3.06)$ & $1.02(0.74,1.40)$ \\
\hline$P$ for trend & & 0.156 & 0.048 & 0.378 \\
\hline \multicolumn{5}{|l|}{ Milk } \\
\hline$<1 /$ week & $95 / 352$ & 1.00 & 1.00 & 1.00 \\
\hline $1 \sim 2 /$ week & $92 / 417$ & $0.82(0.59,1.13)$ & $0.91(0.62,1.32)$ & $1.50(0.84,2.62)$ \\
\hline$\geq 3 /$ week & $152 / 491$ & $1.15(0.86,1.54)$ & $1.27(0.89,1.81)$ & $0.84(0.54,1.32)$ \\
\hline$P$ for trend & & 0.247 & 0.084 & 0.233 \\
\hline
\end{tabular}




\begin{tabular}{|c|c|c|c|c|}
\hline Foods & $\mathrm{N}(\text { Yes/No })^{*}$ & Unadjusted $\mathrm{OR}_{1}(95 \% \mathrm{CI})^{\dagger}$ & Adjusted $\mathrm{OR}_{2}(95 \% \mathrm{CI})^{\ddagger}$ & Adjusted $\mathrm{OR}_{3}(95 \% \mathrm{CI})^{\mathrm{s}}$ \\
\hline \multicolumn{5}{|l|}{ Eggs } \\
\hline$<1 /$ week & $81 / 297$ & & & \\
\hline $1 \sim 2 /$ week & 126523 & $0.88(0.65,1.21)$ & $0.96(0.65,1.43)$ & $1.11(0.72,1.73)$ \\
\hline$\geq 3 /$ week & $132 / 440$ & $1.10(0.81,1.51)$ & $1.19(0.80,1.78)$ & $1.01(0.61,1.73)$ \\
\hline$P$ for trend & & 0.428 & 0.225 & 0.558 \\
\hline \multicolumn{5}{|l|}{ Fast food } \\
\hline$<1 /$ week & $207 / 784$ & 1.00 & 1.00 & 1.00 \\
\hline $1 \sim 2 /$ week & $115 / 419$ & $1.04(0.80,1.34)$ & $1.10(0.83,1.44)$ & $1.11(0.65,1.92)$ \\
\hline$\geq 3 /$ week & $17 / 57$ & $1.13(0.63,1.94)$ & $1.18(0.64,2.08)$ & $1.04(0.77,1.40)$ \\
\hline$P$ for trend & & 0.642 & 0.433 & 0.879 \\
\hline
\end{tabular}

Table 2. The association between food consumption and rhinitis among primary school children. ${ }^{*} \mathrm{~N}$, sample size. Yes represents the number of students who had rhinitis and No represents the number of students who did not have rhinitis. ${ }^{\dagger} \mathrm{OR}_{1}$, never adjustment for any variables. ${ }^{\ddagger} \mathrm{OR}_{2}$, adjustment for age, body mass index, gender, average size of house for each member, concentration of $\mathrm{PM}_{2.5}$ in each school, education of father, education of mother, passive smoking at home, keeps a pet at home, has a carpet at home, has mould at home, has a plant at home, home renovation, burns incense/mosquito coils at home, other respiratory diseases, $\log 10$ (total chemical burden score), family history of atopic diseases, and weekly physical activity. ${ }^{\S} \mathrm{OR}_{3}$, adjustment for variable in $\mathrm{OR}_{2}$ as well as all foods.

This study found that both nuts and potatoes consumption with thrice or more per week was associated an increased risk of rhinitis. This was consistent to the results form ISAAC Phase Three study which reporting that both nuts and potatoes consumption of thrice or more per week were associated with increased risk of both rhinoconjunctivitis and severe rhinoconjunctivitis in children aged 13-14 years ${ }^{35}$. In contrast, rice consumption was related to the decreased risk of rhinitis in our study, this was consistent to the results from a cross-sectional study in Turkey schoolchildren ${ }^{41}$ and from ISAAC Phase One study ${ }^{36}$. We observed that rice intake of $\geq 3$ times/week had OR of 0.63 and rice intake of $1 \sim 2$ times/week had OR of 0.43 . The possible reason for this may be due to the limited sample size in each category. However, when we considering the effects of both confounders and other groups of food, the significant association with was only observed in rice, which playing a protective role. This indicates that there might have some joint effects or complicated cross-reactivity among different groups of food. Using single-food approach is valuable for understanding potential biological mechanisms underlying observed associations, but it is limited by the multicollinearity of dietary intake variables and the inability to detect small effects of single dietary components; however, the cumulative effects of multiple dietary ingredients included in a dietary pattern may be sufficiently large to be detectable.

Our study used principle component factor analysis to define dietary patterns and found that dietary pattern II which had higher factor loadings of legumes, butter, nuts and potatoes was associated with an increased risk of rhinitis in school-age children, no matter pattern score as continuous variable or as categorical variable. Consistent results were observed in sensitivity analysis and stratified analysis, though the effect in females was marginally significant. Possible mechanism maybe due to that food-induced allergic reactions are responsible for a variety of symptoms involving the skin, gastrointestinal tract, and respiratory tract and might be caused by IgE-mediated and non-IgE-mediated (cellular) mechanisms ${ }^{42}$. A minority of food, including peanut, tree nuts, soy, was thought to cause the majority of allergic reactions ${ }^{43}$. Sensitization, mainly to peanuts, is occurring in very young children, and multiple peanut/nut allergies appear progressively ${ }^{44}$. Leguminous crops are also reported to be source of IgE mediated reactions in Mediterranean and Asian countries ${ }^{45}$. People with soybean allergy sensitized to Gly $\mathrm{m} 5$ or Gly $\mathrm{m} 6$ allergens may be at greater risk of experiencing severe allergic reactions ${ }^{46}$. In addition, cross-reactivity was also observed among different legumes, between legumes and nuts and between legumes and other allergen ${ }^{47}$. Butter is extracted from animal fat and it has an abundance of saturated fatty acids. A high intake level of saturated fatty acids may modify serum cholesterol levels and influence the arachidonic acid in the cell membrane ${ }^{48}$. Both serum cholesterol and arachidonic acid can affect lymphocyte function, which further lead to reinforcement in bronchial reactivity and reversible airway obstruction ${ }^{49}$. Margarine was included in butter in this study. Margarine consumption was also reported to be associated with allergic sensitization in children ${ }^{50,51}$. Margarine contains lots of linoleic acid which is a precursor of PGE2, which in turn may promote allergic sensitization by inhibiting the formation of IFN $-\gamma^{52,53}$. Potatoes generally contains a higher level of protein than other tubers or cereals, and up to $40 \%$ of the protein could be patatin, which belongs to a family of immunological identical isoforms of glycoproteins and are responsible for allergic reactions in children ${ }^{54,55}$. We observed that, when taken pattern scores as categorical variables, no significant association was observed in both two groups based on median of age and based on genders. This might due to the smaller sample size in subgroup analysis.

In contrast, dietary pattern I, which had a higher factor loading of meat, seafood, fruits, vegetables, cereals, rice, milk and eggs, was not significantly associated with any risk of rhinitis. Regarding the individual groups of food included in pattern I, there are a number of studies which investigated their relationships with rhinitis, but the majority of these studies had a cross-sectional design and the results were inconsistent ${ }^{25,56-60}$. Dietary pattern III, which had a higher factor loading of fast food, was not related to any risk of rhinitis. This was consistent to results from above analysis on the single group of food. ISAAC Phase Three study reported that the consumption 


\begin{tabular}{|c|c|c|c|c|}
\hline & $\mathrm{N}\left(\right.$ Yes/No) ${ }^{*}$ & Unadjusted $\mathrm{OR}_{1}(95 \% \mathrm{CI})^{\dagger}$ & Adjusted $\mathrm{OR}_{2}(95 \% \mathrm{CI})^{\ddagger}$ & Adjusted $\mathrm{OR}_{3}(95 \% \mathrm{CI})^{\mathrm{s}}$ \\
\hline \multicolumn{5}{|l|}{ Pattern I } \\
\hline Tertile 1 & $120 / 413$ & 1.00 & 1.00 & 1.00 \\
\hline Tertile 2 & $109 / 424$ & $0.88(0.66,1.19)$ & $0.88(0.63,1.23)$ & $0.93(0.664,1.32)$ \\
\hline Tertile 3 & $110 / 423$ & $0.89(0.67,1.2)$ & $0.89(0.64,1.25)$ & $1.02(0.71,1.48)$ \\
\hline$p$ for trend & & 0.454 & 0.547 & 0.862 \\
\hline Every-1 score increment & $339 / 1,260$ & $0.96(0.85,1.08)$ & $0.97(0.82,1.15)$ & $1.01(0.85,1.21)$ \\
\hline \multicolumn{5}{|l|}{ Pattern II } \\
\hline Tertile 1 & $96 / 437$ & 1.00 & 1.00 & 1.00 \\
\hline Tertile 2 & $119 / 414$ & $1.31(0.97,1.77)$ & $1.22(0.86,1.71)$ & $1.18(0.82,1.68)$ \\
\hline Tertile 3 & $124 / 409$ & $1.38(1.02,1.86)$ & $1.35(1.03,1.84)$ & $1.34(1.01,1.87)$ \\
\hline$p$ for trend & & 0.036 & 0.045 & 0.046 \\
\hline Every-1 score increment & $339 / 1,260$ & $1.16(1.03,1.3)$ & $1.19(1.05,1.40)$ & $1.19(1.05,1.35)$ \\
\hline \multicolumn{5}{|l|}{ Pattern III } \\
\hline Tertile 1 & $102 / 431$ & 1.00 & 1.00 & 1.00 \\
\hline Tertile 2 & $127 / 406$ & $1.32(0.99,1.78)$ & $1.29(0.92,1.8)$ & $1.27(0.90,1.80)$ \\
\hline Tertile 3 & $110 / 423$ & $1.1(0.81,1.49)$ & $1.09(0.80,1.48)$ & $1.11(0.80,1.54)$ \\
\hline$p$ for trend & & 0.549 & 0.599 & 0.561 \\
\hline Every-1 score increment & $339 / 1,260$ & $1.02(0.9,1.15)$ & $1.02(0.90,1.15)$ & $1.03(0.90,1.16)$ \\
\hline
\end{tabular}

Table 3. The association between dietary patterns and rhinitis among primary school children. ${ }^{*} \mathrm{~N}$, sample size. Yes represents the number of students who had rhinitis and No represents the number of students who did not have rhinitis. ${ }^{\dagger} \mathrm{OR}_{1}$, never adjustment for any variables. ${ }^{\ddagger} \mathrm{OR}_{2}$, adjustment for age, body mass index, gender, average size of house for each member, concentration of $\mathrm{PM}_{2.5}$ in each school, education of father, education of mother, passive smoking at home, keeps a pet at home, has a carpet at home, has mould at home, has a plant at home, home renovation, burns incense/mosquito coils at home, other respiratory diseases, $\log 10$ (total chemical burden score), family history of atopic diseases, and weekly physical activity. ${ }^{\circledR} \mathrm{OR}_{3}$, adjustment for variable in $\mathrm{OR}_{2}$ as well as three patterns.

of fast food with thrice or more per week was associated increased risk of rhinitis and other allergic diseases ${ }^{35}$. The conflicted results might be due to the variance of dietary habits and dietary preference.

In comparison with other study with factor analysis or principal component analysis, two dietary patterns were extracted by using factor analysis in cross-sectional study in Taiwan school-age children ${ }^{21}$. Both patterns were observed to be associated with and increased risk of allergic rhinitis, However, this study ${ }^{21}$ had some conflicts itself from the information presented: high-protein, high-fat, and western diet pattern was associated with increased risk of allergic rhinitis when score as the continuous variables but not when as categorical variables; the health pattern was seemed to be associated with an increased risk of rhinitis when pattern score takes as both continuous and categorical variables whereas the author did not provide any reason.

Food-induced allergic rhinitis is also occurs together with other food allergy symptoms such as asthma, eczema, oral allergic manifestations ${ }^{61}$. Persistent wheezing also was report to be a risk factor in the development of allergic rhinitis in children after five years of age ${ }^{62}$. In this study, consistent adverse effect by pattern II was obtained after removing the children with other respiratory diseases. Family history of atopic disease might influence the association ${ }^{63}$. However, in this study, similar adverse effect by pattern II were obtained after removing those children with family history of atopic disease, which indicate that the pattern effect did not attribute to the effects of family history of atopic disease.

Dietary pattern is a better and more comprehensive approach, by which the holistic effects of diet can be explored. PCA is a realistic approach to identifying distinct dietary patterns which represent the whole profile of the diet consumed ${ }^{13}$. Besides, dietary patterns by the principle component analysis have ability to overcome issues pertaining to the multicollinearity of food, nutrients, and other dietary constituents, and the cumulative effects of multiple dietary ingredients included in a dietary pattern may be sufficiently large to be detectable ${ }^{64}$. By using PCA, three dietary patterns were defined in this study. The overall value of Kaiser-Meyer-Olkin was 0.94 and $p$ value for Bartlett's test of sphericity was less than 0.001 , suggesting a proper sample size with which to perform $\mathrm{PCA}^{40}$. The individual measures of sampling adequacy for each item ranged from 0.86 (nuts) to 0.96 (seafood), ensuring an acceptable level of accuracy of measurement for both patterns in our study. The communality for each component was large than 0.50 , which means that the factor loadings derived from principal component analysis can be used for further analysis.

The strengths of the present study include the prospective cohort study design, relatively large sample size, high response rate and adjustment for a wide range of confounders. Another advantage is that the reproducibility test showed there were moderate association and moderate agreement for the food frequency questionnaire. All students were survey in the same season in both baseline survey and follow-up survey. We also examined the relationship between outcomes and baseline dietary consumption by using same analytic approach: three similar patterns were extracted; pattern II was associated with an increased risk of rhinitis when adjusted for confounders (OR: 1.44, 95\% CI: 1.06-1.95, p-trend: 0.020) and adjusted for confounders as well as three patterns (OR: 1.45, 95\% CI: 1.07-1.97, p-trend: 0.021) when comparing the highest tertile with the lowest tertile of pattern scores. The consistent results were sufficiently close to make the validity of our questionnaire within an acceptable range. 
However, there are limitations. Firstly, the food frequency questionnaire was applied over last 12 month, which might lead to somewhat recall bias. However, the reproducibility test proved higher consistent in the responses to each group of food. Secondly, multiple tests for the 13 food items might result in false-positive associations, but the results for individual groups of food prompted us to conduct dietary pattern analysis to surmount the shortcomings of traditional approach based on single dietary ingredient. Thirdly, the intake amount of each food was not collected and the total energy intake was not available, which is similar to other previous studies ${ }^{48,57}$. This limitation rendered us to take them into account directly. In this study, we made adjustments for body mass index and weekly physical activity which were suggested as an indirect alternative approach ${ }^{27,65}$. Fourthly, there were only 13 groups of food were included in the questionnaire. Fewer food groups used in the pattern analysis may reduce the study power. A more detailed and comprehensive food frequency questionnaire should be developed in future studies to warrant more in-depth and thorough analyses. Finally, information on rhinitis was retrieved from questionnaire and it refers to non-infectious rhinitis. We were not able to exclude non-allergic rhinitis such as vasomotor cases in the present study. However, the proportion of non-allergic rhinitis within non-infectious generally is very low in children and should not affect our results.

In conclusion, this study found that a diet pattern with higher levels of consumption of legumes, butter, nuts and potatoes may increase the risk of rhinitis in primary school children. Results from this study suggest that prevention strategies should consider not only single dietary ingredients but also complex dietary patterns.

\section{References}

1. Thomsen, S. F. Epidemiology and natural history of atopic diseases. Eur Clin Respir J 2 (2015).

2. The Global Asthma Network. The Global Asthma Report 2014. (Auckland, New Zealand 2014).

3. Braman, S. S. The global burden of asthma. Chest 130, 4S-12S (2006)

4. Asher, I. \& Pearce, N. Global burden of asthma among children. Int J Tuberc Lung Dis 18, 1269-1278 (2014).

5. Akdis, C. A., Hellings, P. W. \& Agache, I. Global Atlas of Allergic Rhinitis and Chronic Rhinosinusitis. http://www.eaaci.org/ globalatlas/ENT_Atlas_web.pdf (European Academy of Allergy and Clinical Immunology, 2015).

6. Penard-Morand, C. et al. Prevalence of food allergy and its relationship to asthma and allergic rhinitis in schoolchildren. Allergy $\mathbf{6 0}$, 1165-1171 (2005).

7. Julia, V., Macia, L. \& Dombrowicz, D. The impact of diet on asthma and allergic diseases. Nat Rev Immunol 15, 308-322 (2015).

8. Allen, S., Britton, J. R. \& Leonardi-Bee, J. A. Association between antioxidant vitamins and asthma outcome measures: systematic review and meta-analysis. Thorax 64, 610-619 (2009).

9. Nurmatov, U., Devereux, G. \& Sheikh, A. Nutrients and foods for the primary prevention of asthma and allergy: systematic review and meta-analysis. J Allergy Clin Immunol 127, 724-733 e721-730 (2011).

10. Yang, Z. et al. Frequency of food group consumption and risk of allergic disease and sensitization in schoolchildren in urban and rural China. Clin Exp Allergy 45, 1823-1832 (2015).

11. Willers, S. M. et al. Childhood diet and asthma and atopy at 8 years of age: the PIAMA birth cohort study. Eur Respir J 37, $1060-1067$ (2011).

12. Luna Maria de Fátima Gomes de. Prevalência de asma e rinite e fatores associados à asma em escolares de Fortaleza Doctorate thesis, Universidade Federal do Rio Grande do Sul (Available: http://hdl.handle.net/10183/132106 2015).

13. Hu, F. B. Dietary pattern analysis: a new direction in nutritional epidemiology. Curr Opin Lipidol 13, 3-9 (2002).

14. Mozaffarian, D. Foods, nutrients, and health: when will our policies catch up with nutrition science? The Lancet Diabetes \& Endocrinology 5, 85-88 (2017).

15. de Batlle, J., Garcia-Aymerich, J., Barraza-Villarreal, A., Anto, J. M. \& Romieu, I. Mediterranean diet is associated with reduced asthma and rhinitis in Mexican children. Allergy 63, 1310-1316 (2008).

16. Lv, N., Xiao, L. \& Ma, J. Dietary pattern and asthma: a systematic review and meta-analysis. J Asthma Allergy 7, 105-121 (2014).

17. Hendaus, M. A., Jomha, F. A. \& Ehlayel, M. Allergic diseases among children: nutritional prevention and intervention. Ther Clin Risk Manag 12, 361-372 (2016).

18. Garcia-Marcos, L. et al. Influence of Mediterranean diet on asthma in children: a systematic review and meta-analysis. Pediatr Allergy Immunol 24, 330-338 (2013).

19. de Cassia Ribeiro Silva, R. et al. Dietary Patterns and Wheezing in the Midst of Nutritional Transition: A Study in Brazil. Pediatr Allergy Immunol Pulmonol 26, 18-24 (2013).

20. Patel, S. et al. Cross-sectional association of dietary patterns with asthma and atopic sensitization in childhood - in a cohort study. Pediatr Allergy Immunol 25, 565-571 (2014).

21. Lin, Y. P. et al. Associations between Respiratory Diseases and Dietary Patterns Derived by Factor Analysis and Reduced Rank Regression. Ann Nutr Metab 68, 306-314 (2016).

22. Tromp, I. I. et al. Dietary patterns and respiratory symptoms in pre-school children: the Generation R Study. Eur Respir J 40, 681-689 (2012).

23. Chatzi, L. et al. Protective effect of fruits, vegetables and the Mediterranean diet on asthma and allergies among children in Crete. Thorax 62, 677-683 (2007).

24. Rice, J. L. et al. Association Between Adherence to the Mediterranean Diet and Asthma in Peruvian Children. Lung (2015).

25. Tamay, Z., Akcay, A., Ergin, A. \& Guler, N. Effects of dietary habits and risk factors on allergic rhinitis prevalence among Turkish adolescents. Int J Pediatr Otorhinolaryngol 77, 1416-1423 (2013).

26. Chatzi, L. \& Kogevinas, M. Prenatal and childhood Mediterranean diet and the development of asthma and allergies in children. Public Health Nutr 12, 1629-1634 (2009).

27. Willett, W. Nutritional epidemiology. 3rd edn (Oxford University Press, 2013).

28. Liu, X. et al. Frequent use of household cleaning products is associated with rhinitis in Chinese children. J Allergy Clin Immunol 138, 754-760 e756 (2016).

29. Wong, C. C. Y., Lao, X. Q., Chang, H. H. L. \& Yu, I. T. S. Exposure to household cleaning products and respiratory health effects in young school children. in ISEE Annual Conference: from local to global: advancing science for policy in environmental health (ehp) (2014).

30. Lao X. Q. et al. Prospective cohort study on health effects of school environmental air quality in Hong Kong School Children. in Indoor Air 2014 - 13th International Conference on Indoor Air Quality and Climate. 687-690 (International Society of Indoor Air Quality and Climate) (2014).

31. European Community Respiratory Health Survey II Steering Committee. The European Community Respiratory Health Survey II. Available from: http://www.ecrhs.org/ECRHS\%20II.htm (2014).

32. Ferris, B. G. Epidemiology Standardization Project (American Thoracic Society). Am Rev Respir Dis 118, 1-120 (1978).

33. Ellwood, P. et al. The international study of asthma and allergies in childhood (ISAAC): phase three manual. Available from: http:// isaac.auckland.ac.nz/phases/phasethree/phasethreemanual.pdf (2000). 
34. Ellwood, P. et al. The international study of asthma and allergies in childhood (ISAAC): phase three environmental questionnaire 13-14 years. Available from: http://isaac.auckland.ac.nz/phases/phasethree/environmentalquestionnaire/environmentalquestionnaire13_14. $\operatorname{pdf}(2000)$.

35. Ellwood, P. et al. Do fast foods cause asthma, rhinoconjunctivitis and eczema? Global findings from the International Study of Asthma and Allergies in Childhood (ISAAC) phase three. Thorax 68, 351-360 (2013).

36. Ellwood, P. et al. Diet and asthma, allergic rhinoconjunctivitis and atopic eczema symptom prevalence: an ecological analysis of the International Study of Asthma and Allergies in Childhood (ISAAC) data. ISAAC Phase One Study Group. Eur Respir J 17, 436-443 (2001).

37. DeVellis, R. F. Scale development: theory and applications. 3rd edn (SAGE, 2012).

38. Altman, D. G. Practical statistics for medical research. (Chapman and Hall, 1991)

39. Liu, X. et al. Frequent use of household cleaning products is associated with rhinitis in Chinese children. J Allergy Clin Immunol, doi: 10.1016/j.jaci.2016.03.038 (2016).

40. Johnson, R. A. \& Wichern, D. W. Applied multivariate statistical analysis. 6th edn (Pearson Prentice Hall, 2007).

41. Tamay, Z., Akcay, A., Ergin, A. \& Guler, N. Dietary habits and prevalence of allergic rhinitis in 6 to 7 -year-old schoolchildren in Turkey. Allergol Int 63, 553-562 (2014).

42. Sampson, H. A. et al. Food allergy: a practice parameter update-2014. J Allergy Clin Immunol 134, 1016-1025 e1043 (2014).

43. Boyce, J. A. et al. Guidelines for the diagnosis and management of food allergy in the United States: report of the NIAID-sponsored expert panel. J Allergy Clin Immunol 126, S1-58 (2010).

44. Ewan, P. W. Clinical study of peanut and nut allergy in 62 consecutive patients: new features and associations. BMJ 312, 1074-1078 (1996).

45. Pascual, C. Y. et al. Allergy to lentils in Mediterranean pediatric patients. J Allergy Clin Immun 103, 154-158 (1999).

46. Nicolaou, N. \& Custovic, A. Molecular diagnosis of peanut and legume allergy. Curr Opin Allergy Clin Immunol 11, 222-228 (2011).

47. Verma, A. K., Kumar, S., Das, M. \& Dwivedi, P. D. A Comprehensive Review of Legume Allergy. Clin Rev Allergy Immunol 45, 30-46 (2013).

48. de Pablo, M. A. \& Alvarez de Cienfuegos, G. Modulatory effects of dietary lipids on immune system functions. Immunol Cell Biol 78, $31-39(2000)$

49. Damera, G. \& Panettieri, R. A. Does airway smooth muscle express an inflammatory phenotype in asthma? Br J Pharmacol 163, $68-80$ (2011).

50. Bolte, G. et al. Margarine consumption and allergy in children. Am J Respir Crit Care Med 163, 277-279 (2001).

51. Sausenthaler, S. et al. Margarine and butter consumption, eczema and allergic sensitization in children. The LISA birth cohort study. Pediatr Allergy Immunol 17, 85-93 (2006).

52. Black, P. N. \& Sharpe, S. Dietary fat and asthma: Is there a connection? European Respiratory Journal 10, 6-12 (1997).

53. Black, P. N. The prevalence of allergic disease and linoleic acid in the diet. J Allergy Clin Immunol 103, 351-352 (1999).

54. Zaheer, K. \& Akhtar, M. H. Recent advances in potato production, usage, nutrition-a Review. Crit Rev Food Sci Nutr (2014).

55. Jorgensen, M., Bauw, G. \& Welinder, K. G. Molecular properties and activities of tuber proteins from starch potato cv. Kuras. J Agric Food Chem 54, 9389-9397 (2006).

56. Rosenlund, H. et al. Fruit and vegetable consumption in relation to allergy: disease-related modification of consumption? J Allergy Clin Immunol 127, 1219-1225 (2011).

57. Farchi, S. et al. Dietary factors associated with wheezing and allergic rhinitis in children. Eur Respir J 22, 772-780 (2003).

58. Kim, J. L. et al. Current asthma and respiratory symptoms among pupils in relation to dietary factors and allergens in the school environment. Indoor Air 15, 170-182 (2005).

59. Saadeh, D. et al. Prevalence and association of asthma and allergic sensitization with dietary factors in schoolchildren: data from the french six cities study. BMC Public Health 15, 993 (2015).

60. Barraza-Villarreal, A., Gutierrez, R., Escamilla, C., Hernandez-Cadena, L. \& Romieu, I. Dietary factors associated with wheezing and allergic rhinitis in schoolchildren from Cuernavaca Mexico. Epidemiology 17, S230-S230 (2006).

61. Cingi, C., Demirbas, D. \& Songu, M. Allergic rhinitis caused by food allergies. Eur Arch Otorhinolaryngol 267, 1327-1335 (2010).

62. Cetinkaya, F. \& Atalay, O. O. Effects of wheezing in early childhood in the development of allergic rhinitis in later years. Asia Pac Allergy 4, 37-41 (2014).

63. Alford, S. H. et al. Parental history of atopic disease: disease pattern and risk of pediatric atopy in offspring. J Allergy Clin Immunol 114, 1046-1050 (2004).

64. Miller, P. E. et al. Diet index-based and empirically derived dietary patterns are associated with colorectal cancer risk. J Nutr 140, $1267-1273(2010)$.

65. Rhee, J. J. et al. Comparison of methods to account for implausible reporting of energy intake in epidemiologic studies. Am J Epidemiol 181, 225-233 (2015).

\section{Acknowledgements}

The authors would like to thank the school principals, teachers, students, and their parents for supporting this project. The study was funded by the Health Medical Research Fund (No. 11121101) and the Hong Kong General Research Fund (No. CU11688). The funders had no role in the design, analysis or writing of this manuscript.

\section{Author Contributions}

X.Q.L. conceptualized and designed this study; L.X.T., C.W. and Z.L.Z. collected the data under the supervision of X.Q.L. and I.Y.; X.D.L. and L.X.T. analyzed the data; X.D.L. prepared figure; Z.L.Z. did the test-retest study; X.D.L. and X.Q.L. wrote the manuscript; X.Q.L., A.P.S.L., Y.I., E.K.Y. and A.L. edited and reviewed the manuscript. All co-authors provided critical comments and approved the final version.

\section{Additional Information}

Supplementary information accompanies this paper at http://www.nature.com/srep

Competing Interests: The authors declare no competing financial interests.

How to cite this article: Liu, X. et al. Dietary patterns and the risk of rhinitis in primary school children: a prospective cohort study. Sci. Rep. 7, 44610; doi: 10.1038/srep44610 (2017).

Publisher's note: Springer Nature remains neutral with regard to jurisdictional claims in published maps and institutional affiliations. 
(c) (i) This work is licensed under a Creative Commons Attribution 4.0 International License. The images or other third party material in this article are included in the article's Creative Commons license, unless indicated otherwise in the credit line; if the material is not included under the Creative Commons license, users will need to obtain permission from the license holder to reproduce the material. To view a copy of this license, visit http://creativecommons.org/licenses/by/4.0/

(C) The Author(s) 2017 